\title{
ANALISIS ANTRIAN PADA PELAYANAN ALAT RTG DI LAPANGAN PENUMPUKAN TERMINAL BERLIAN (PT BERLIAN JASA TERMINAL INDONESIA)
}

\author{
Rachmah Agus Triati ${ }^{1}$, Henita Rahmayanti ${ }^{2}$ \\ Email:rahmah12@ gmail.com $^{1}, \underline{\text { henita.rahmayanti@unj.ac.id }}^{2}$ \\ ${ }_{2}^{1}$ Prodi D III Transportasi, Fakultas Teknik - Universitas Negeri Jakarta \\ Prodi D III Transportasi, Fakultas Teknik - Universitas Negeri Jakarta
}

\begin{abstract}
Abstrak. Laporan tugas akhir ini bertujuan untuk mengetahui model antrian petikemas pada lapangan penumpukkan di Termina Berlian, sekaligus sebagai persyaratan kelulusan program studi Manajemen Pelabuhan Universitas Negeri Jakarta. Dari hasil perhitungan kinerja sistem antrian pada lapangan penumpukan terminal berlian menunjukkan bahwa bulan paling sibuk terjadi pada bulan Mei dengan jumlah kedatangan petikemas sebanyak 8199 box dan kedatangan petikemas paling sepi terjadi pada bulan Juni dengan jumlah petikemas sebanyak 5332 box. Hasil perhitungan probabilitas tidak terdapat dalam sistem antrian terjadi pada bulan Februari dan Mei sebesar 0\%. Hal itu menunjukkan tingkat kesibukan alat RTG mencapai $100 \%$ dan persentase tingkat kesibukan paling kecil dari alat RTG pada bulan April dan Juni sebesar $20 \%$ yang menunjukkan kondisi paling sepi dalam sistem antrian di lapangan penumpukan berlian. Tingginya tingkat kedatangan petikemas di tambah sempitnya lapangan penumpukan berlian yang akhirnya melampaui batas kapasitas dari alat RTG sehingga menimbulkan ketidakseimbangan antara tingkat kedatangan dengan tingkat pelayanan dari terminal berlian.
\end{abstract}

Kata kunci: : analisis, petikemas, lapangan penumpukkan

\begin{abstract}
Abstrac, This final task report aims to determine the model of the container queue at the diamond Terminal, as well as the graduation requirement of the Jakarta State University management course. From the calculation results of the system performance of the queue in the field of stacking the diamond terminal shows that the busiest month occurred in May with the number of containers arrival as much as 8199 boxes and the arrival of the most deserted containers occurred in the month June with a number of containers as much as 5332 boxes. The probability calculation results are not contained in the system queuing occurring in February and may by 0\%. It shows the busyness of the RTG tool reaches 100\% and the percentage of the most small bustle of the RTG tool in April and June by 20\% showing the most lonely conditions in the queue system in the field of diamond buildup. The high level of arrival of containers in addition to the complexity of the diamond buildup field that eventually exceeded the capacity limit of the $R T G$ tool thus giving rise to an imbalance between the arrival rate and the service level of the diamond terminal.
\end{abstract}

Keyword: analysis, containers, ground-shedping

\section{A. PENDahuluan}

Pertumbuhan ekonomi nasional indonesia sangat dipengaruhi oleh kestrategisan wilayah kelautan. Pelabuhan di tanah air mengalami kemajuan yang cukup pesat, hal ini terlihat dengan ramainya aktivitas perdagangan dipelabuhan dan Indonesia sangat memegang andil perdagangan dunia. Seiring dengan perkembangan pelabuhan yang semakin maju, perusahaan harus bekerja secara efektif dan efisien. Peningkatkan mutu dan kualitas pelayanan yang berkualitas baik akan menciptakan standar pelayanan petikemas yang berorientasi pada kepuasan pelanggan.

PT Berlian Jasa Terminal Indonesia merupakan salah satu perusahaan yang bisnis utamanya Operator Terminal Bongkar Muat Petikemas Domestik di Berlian, maka pengelolaan pelayanan jasa bongkar muat harus memberikan pelayanan yang baik. Persaingan yang terjadi pada perusahaan bongkar muat mengharuskan perusahaan untuk meningkatkan pelayanan kepada pengguna jasa agar dapat memperthankan kepercayaan pengguna jasa. Pengguna jasa yang mendapatkan pelayanan baik akan terus berkomitmen untuk menjalin kerjasama dengan perusahaan, jika pelayanan yang diberikan kurang maka tidak akan menutup kemungkinan bahwa jumlah pengguna jasa akan mengalami penurunan.

Pelayanan muatan petikemas salah satunya menggunakan fasilitas utama yaitu lapangan penumpukan yang digunakan untuk menumpuk petikemas. Terminal Berlian melakukan kegiatan penumpukan di 
petikemas menggunakan alat angkat, alat angkat yang biasa dipakai adalah Rubber Tyred Gantry Crane, fork lift truck, reach stacker dan top / side loader. Berdasarkan fenomena yang ada di Terminal Berlian sering terjadi antrian pada pintu masuk gate dan lapangan penumpukkan. Dari hasil observasi antrian terjadi dipengaruhi oleh banyaknya kapal sandar, adanya waktu tunggu saat pergantian jam kerja (shift operator), saat jam istirahat makan siang, adanya trouble alat, kemudian adanya kegiatan pembangunan jalan disekitar Terminal Berlian, dan kepadatan sering terjadi pada sore hari sekitar pukul 16.00 hingga 19.00 WIB.

Antrian pada pintu masuk gate dan lapangan penumpukkan di Terminal Berlian dapat dilihat dari panjangnya antrian truk yang berada di sekitar lapangan penumpukkan dan area Terminal Berlian. Antrian yang panjang menyebabkan terjadinya waktu tunggu yang lama sehingga menyebabkan pelanggan merasa tidak puas dengan pelayanan yang diberikan perusahaan dan memungkinkan pelanggan akan memilih perusaahaan lain. Jika hal ini terus terjadi tanpa ada usaha perbaikan, maka bisa dipastikan perusahaan akan mengalami kerugian karena jumlah pelanggan akan menurun. Oleh karena itu perusahaan harus dapat menentukan jumlah fasilitas pelayanan yang optimal dan diharapkan juga perusahaan mampu menciptakan sistem antrian yang optimal sehingga dapat mencegah terjadinya waktu tunggu yang lama akan mampu memberikan keuntungan bagi pihak perusahaan maupun pelanggan, waktu tunggu yang cepat akan meningkatkan produktivitas bagi perusahaan karena memungkinkan terjadinya pelayanan yang lebih banyak pada waktu yang singkat.

Terminal Berlian diharapkan mampu memberikan pelayanan terbaik kepada pengguna jasa baik dari segi sistem-sistemnya, fasilitas pelayanan maupun sumber daya manusianya, karena jika perusahaan tidak segera melakukan perbaikan maka tidak menutup kemungkinan pada masa yang akan datang tingkat pengguna jasa atau pelanggan yang dimiliki perusahaan akan mengalami penurunan karena terjadinya kinerja pelayanan yang tidak optimal.

Peneliti tertarik untuk mengangkat permasalahan mengenai antrian pada perusahaan kepelabuhanan karena peneliti meyakini bahwa sistem antrian yang buruk dan menimbulkan terjadinya antrian yang panjang akan mengakibatkan rendahnya tingkat kepuasan pelanggan. Pada akhirnya hal tersebut akan menyebabkan kerugian bagi perusahaan itu sendiri karena hilangnya komitmen pelanggan untuk menggunakan jasa mereka.

Namun jika ada upaya yang dilakukan oleh pihak perusahaan untuk meningkatkan kinerja pelayanan khususnya pada masalah antrian, penulis yakin perusahaan tersebut akan memperoleh keuntungan yang berlipat baik dari segi finansial maupun jumlah pelanggan yang dimiliki, karena dengan waktu tunggu yang cepat tentu akan meningkatkan produktivitas.

Penelitian dfokuskan pada fenomena antrian pelayanan muat petikemas di lapangan penumpukkan pada Terminal Berlian. Dengan menggunakan teori antrian pelayanan muat petikemas di lapangan penumpukkan Terminal Berlian akan bertujuan mengetahui rata-rata waktu tunggu petikemas dalam antrian dan rata-rata waktu tunggu petikemas dalam antrian dan rata-rata waktu pelayanan alat RTG dalam satuan waktu tertentu. Berdasarkan pengamatan selama melakukan Magang pada BJTI PORT masalah sebagai berikut : 1) bagaimana model antrian petikemas pada lapangan penumpukkan di Terminal Berlian. 2) apa saja penyebab terjadinya masalah antrian pada lapangan penumpukkan petikemas di Terminal Berlian.

Batasan masalah yaitu pada masalah antrian dan kinerja pelayanan muat petikemas di lapangan penumpukkan blok H dengan alat RTG B10 Terminal Berlian. Rata-rata waktu tunggu petikemas dalam antrian dan pelayanan alat RTG dalam satuan waktu tertentu. Berdasarkan identifikasi dan batasan masalah di atas, maka pokok permasalahan yang akan dibahas dalam penyusunan tugas akhir ini adalah "bagaimana sistem antrian yang terjadi pada bagian Container Yard atau lapangan penumpukan di Terminal Berlian pada BJTI PORT." Tujuan dalam penelitian ini yaitu : 1) mengetahui model antrian petikemas pada lapangan penumpukkan di Terminal Berlian. 2) mengindentifikasi penyebab terjadinya masalah antrian pada lapangan penumpukkan petikemas di Terminal Berlian.

\section{B. METODE PENELITIAN}

Dalam pembahasan serta beberapa keterangan data yang diperlukkan untuk mengolahnya dalam penulisan karya ilmiah penulis menggunakan data yang dilakukan dengan mengamati secara langsung atas fakta yang terjadi di lapangan, adapun data tersebut terbagi menjadi dua, yaitu :

1. Data Sekunder

Data sekunder pada penelitian ini data yang digunakan adalah data internal perusahaan yaitu Data Produksi RTG tahun 2019, pada bulan Januari 2019 - Juni 2019 . Data yang di peroleh akan diolah 
kedalam bentuk tabel, grafik maupun diagram. Data dapat dilihat pada lampiran 1 hasil data produksi RTG B10 Januari 2019 sampai lampiran 6 hasil data produksi RTG B10 Juli 2019.

2. Data Primer, pada penelitian ini data yang digunakan adalah data informasi yang diperoleh langsung dari narasumber melalui wawancara dengan pihak manajemen Terminal Berlian. Hasil Wawancara dapat dlihat pada lampiran 16 hasil wawancara dengan pihak BJTI dan lampiran 17 hasil wawancara dengan pihak BJTI.

\section{HASIL DAN PEMBAHASAN}

Data produksi dalam penelitian ini dilakukan selama 6 bulan dari bulan januari 2019 sampai juni 2019 Terminal Berlian melakukan kegiatan produksi 24 jam dengan pola kerja 1 hari 3 shift, dimana satu shiftnya 8 jam. Total waktu pengamatan selama 6 bulan adalah 4064 jam.

Tabel 1 Rata - Rata Jumlah Kedatangan dan Waktu Pelayanan Periode Januari 2019 - Juni 2019

\begin{tabular}{|l|l|l|}
\hline \multicolumn{1}{|c|}{ Bulan } & $\begin{array}{c}\text { Jumlah Kedatangan } \\
\text { (box) }\end{array}$ & $\begin{array}{c}\text { Waktu Pengamatan } \\
\text { (jam) }\end{array}$ \\
\hline Januari 2019 & 6602 & 648 \\
\hline Februari 2019 & 7456 & 672 \\
\hline Maret 2019 & 7715 & 728 \\
\hline April 2019 & 6851 & 704 \\
\hline Mei 2019 & 8199 & 728 \\
\hline Juni 2019 & 5332 & 584 \\
\hline Total Kedatangan & $\mathbf{4 2 1 5 5}$ & $\mathbf{4 0 6 4}$ \\
\hline
\end{tabular}

$$
\begin{aligned}
\text { Rata }- \text { Rata Waktu Pelayanan } & =\frac{\text { Total Waktu Pelayanan }}{\text { Total Jumlah Kedatangan Petikemas }} \\
& =\frac{4064}{42155}=5 \text { menit } 46 \text { detik }
\end{aligned}
$$

$$
\text { Rata }- \text { rata Tingkat Pelayanan }(\mu)=\frac{60}{5 \text { menit } 46 \text { detik }}=11 \text { Box } / \mathrm{Jam}
$$

Dari hasil perhitungan kinerja sistem antrian pada Terminal Berlian memperlihatkan bahwa bulan Februari dan bulan Mei adalah bulan yang paling sibuk. Tingkat kedatangan perjam dalam tiap minggu memiliki rata rata $11 \mathrm{box} / \mathrm{jam}$. Hal ini menunjukkan bahwa keadaan kemungkinan tidak terdapat dalam sistem antrian sebesar $0 \%$, yang artinya kesibukan alat RTG mencapai $100 \%$. Hasil perhitungan pada bulan februari dan mei memperlihatkan hasil dari Ls, Lq, Ws, Wq sama yaitu $\infty$. Artinya tingkat kesibukan alat RTG mencapai batas maksimal. Untuk mengurangi kepadatan yang ada dalam sistem antrian dapat melakukan penambahan alat RTG.

Pada bulan Januari dan Maret Probabilitas tidak adanya petikemas dalam sistem adalah 10\%, artinya kesibukan alat RTG mencapai $90 \%$. Hasil perhitungan Ls adalah 10 dan Lq adalah 9 maka rata - rata dalam setiap jam terdapat 10 petikemas yang berada dalam sistem antrian dimana 1 petikemas sedang mendapat pelayanan dan 9 petikemas sedang menunggu dalam antrian. Hasil perhitungan dari Ws adalah 1 jam dan Wq adalah 0,90 maka setiap petikemas menghabiskan waktu 60 menit untuk mendapatkan pelayanan dengan waktu tunggu yang dibutuhkan oleh petikemas selama menunggu dalam antrian adalah 54 menit.

Pada bulan April dan Juni Probabilitas tidak adanya petikemas dalam sistem adalah 20\%, artinya kesibukan alat RTG mencapai 80\%. Hasil perhitungan Ls adalah 4 dan Lq adalah 3 maka rata - rata dalam setiap jam terdapat 4 petikemas yang berada dalam sistem antrian dimana 1 petikemas sedang mendapat pelayanan dan 3 
petikemas sedang menunggu dalam antrian. Hasil perhitungan dari Ws adalah 0,5 jam dan Wq adalah 0,40 maka setiap petikemas menghabiskan waktu 30 menit untuk mendapatkan pelayanan dengan waktu tunggu yang dibutuhkan oleh petikemas selama menunggu dalam antrian adalah 24 menit.

Analisis $5 \mathrm{w}+1 \mathrm{H}$ adalah analisis untuk melakukan perbaikan terhadap penyebab - penyebab yang menimbulkan antrian petikemas di lapangan penumpukkan Terminal Berlian. Adapun hasil analisis tersebut di masukkan kedalam tabel agar rapih dan mudah untuk dipahami sebagai berikut.

Tabel 2 Analisis 5W +1 H Untuk Perbaikan Terhadap Penyebab - Penyebab Yang Menimbulkan Antrian Petikemas

\begin{tabular}{|c|c|}
\hline $\begin{array}{l}\text { WHAT } \\
\text { (Permasalahan apa yang terjadi?) }\end{array}$ & Adanya antrian pada petikemas di lapangan penumpukan terminal berlian \\
\hline (Ap & $\begin{array}{l}\text { 1. Kondisi lapangan penumpukan petikemas berlian yang sempit } \\
\text { 2. Banyaknya kapal yang sedang melakukan kegiatan bongkar muat } \\
\text { 3. Adanya pergantian shift dan kegiatan istirahat } \\
\text { 4. Adanya pembangunan jalan disekitar terminal berlian } \\
\text { 5. Adanya kerusakan alat }\end{array}$ \\
\hline $\begin{array}{l}\text { WHO } \\
\text { (Siapa yang bertanggung jawab?) }\end{array}$ & Manager On Duty, Staff Operasional Terminal Berlian \\
\hline $\begin{array}{l}\text { When } \\
\text { (Kapan terjadinya?) }\end{array}$ & $\begin{array}{l}\text { 1. Saat truk memasuki area Terminal berlian (gate) } \\
\text { 2. Saat melakukan proses pelayanan di Lapangan penumpukkan }\end{array}$ \\
\hline $\begin{array}{l}\text { Where } \\
\text { (Dimana terjadinya?) }\end{array}$ & $\begin{array}{ll}\text { 1. } & \text { Area Terminal Berlian (Gate) } \\
\text { 2. } & \text { Lapangan Penumpukkan Terminal Berlian }\end{array}$ \\
\hline $\begin{array}{l}\text { How } \\
\text { (Bagaimana usulan perbaikan?) }\end{array}$ & $\begin{array}{l}\text { 1. Mengoptimalkan secara maksimal penggunaan lapangan } \\
\text { penumpukkan serta melakukan kerjasama dengan pihak } \\
\text { perusahaan lain untuk melakukan penambahan depo cy } \\
\text { 2. Penambahan alat RTG pada lapangam Penumpukkan di Terminal } \\
\text { Berlian }\end{array}$ \\
\hline
\end{tabular}

\section{KESIMPULAN}

Kesimpulan, Berdasarkan hasil pengamatan yang dilakukan maka didapatkan beberapa kesimpulan, yaitu:

1. Dari hasil perhitungan kinerja sistem antrian pada lapangan penumpukan terminal berlian menunjukkan bahwa bulan paling tinggi terjadi pada bulan Mei dengan jumlah kedatangan petikemas sebanyak 8199 box dan kedatangan petikemas paling rendah terjadi pada bulan Juni dengan jumlah petikemas sebanyak 5332 box.

2. Dari hasil perhitungan probabilitas tidak terdapat dalam sistem antrian terjadi pada bulan Februari dan Mei sebesar 0\%. Hal itu menunjukkan tingkat kesibukan alat RTG mencapai $100 \%$ dan persentase tingkat kesibukan paling kecil dari alat RTG pada bulan April dan Juni sebesar 20\% yang menunjukkan kondisi paling sepi dalam sistem antrian di lapangan penumpukan berlian.

3. Dari hasil perhitungan pada bulan Februari dan Mei menunjukkan hasil Ls, Lq, Ws, dan Wq yang sama, yakni $\infty$ dimana dalam sistem keadaan real tak terdefinisi, kemudian yang berarti tingkat kesibukan pada lapangan penumpukkan sudah mencapai batas maksimal.

4. Penyebab terjadinya antrian pada lapangan penumpukkan terminal berlian adalah karena tingginya tingkat kedatangan petikemas di tambah sempitnya lapangan penumpukan berlian yang akhirnya melampaui batas kapasitas dari alat RTG sehingga menimbulkan ketidakseimbangan antara tingkat kedatangan dengan tingkat pelayanan dari terminal berlian.

5. Hasil perhitungan rata-rata tingkat kedatangan petikemas perjam dalam tiap bulannya dengan 2 kapasitas alat RTG dalam melayani petikemas per jam yaitu sebanyak 21 box/jam dengan rata rata waktu pelayanan 2 menit 53 detik

\section{E. SARAN}

Saran, Berdasarkan uraian diatas, maka diberikan saran untuk dapat dijadikan sebagai bahan masukan :

1. Guna menunjang kegiatan pelayanan di terminal berlian agar dapat melakukan kerjasama dengan pihak perusahaan lain untuk melakukan penambahan DEPO CY, sehingga apabila perusahaan dapat melayani seluruh petikemas yang datang tanpa ada petikemas yang menunggu lama dalam sistem maka peluang meningkatnya pelayanan akan semakin besar dan menimbulkan kepuasan pada pengguna jasa. 
2.PT. BJTI harus memberikan ketegasan terhadap seluruh karyawan operasional agar dapat memberikan pelayanan yang optimal.

3. Adanya dua alat RTG pada lapangan penumpukan diterminal berlian dapat membantu memperlancar kegiatan operasional dilapangan penumpukkan terminal Berlian.

\section{F. DAFTAR PUSTAKA}

Hariyadi, Eko. 2017. Manajemen Pelabuhan. :PT. Andhika Prasetya Ekawahana.

Kakiay, Thomas J. 2004. Dasar Teori Antrian untuk Kehidupan Nyata. Yogyakarta: Andi.

Nasution, N.M. 2004. Manajemen Jasa Terpadu. Bogor: Ghalia Indonesia Bogor.

Suharso, 2002. Kamus Besar Bahasa Indonesia. Semarang: Widya Karya.

Suyono. 2007. Shipping Pengangutan Intermodal Ekspor Impor Melalui Laut. Edisi Keempat, Percetakan Argya Putra. 